\title{
Quantification of tire and road wear particles in the environment
}

\author{
J. M. Panko, J. A. Chu, M. L. Kreider, B. L. McAtee \\ \& K. M. Unice \\ ChemRisk, LLC, USA
}

\begin{abstract}
Tire and road wear particles (TRWP) are produced during the interaction of a tire with the roadway surface when the vehicle is in motion. In order to assess the potential global environmental and human health impact of TRWP, air and sediment samples were collected in 3 watersheds: the Seine River watershed in France, the Yodo River watershed in Japan, and the Chesapeake Bay watershed in the U.S. TRWP was quantified in these samples using a pyrolysis GC-MS marker specific to tires. A wide diversity of areas were sampled including environmental protection areas, recreational areas, commercial districts, residential zones and more remote rural areas. In all cases, the presence of an identifiable source of vehicle traffic was mandatory. For sediment, the overall average tread concentration was 1000 ppm dry weight with a range of $<14$ to $5800 \mathrm{ppm}$ dry weight $(\mathrm{n}=149)$ and grain size classification as sand or silt/clay was a significant determinant of tread concentration. For air the overall average concentration was $0.080 \mu \mathrm{g} / \mathrm{m}^{3}$ with a range of $<0.002 \mu \mathrm{g} / \mathrm{m}^{3}$ to $0.67 \mu \mathrm{g} / \mathrm{m}^{3}$ $(\mathrm{n}=81)$ and a non-significant trend of increasing average tread particle concentration in air with increased population density and traffic load. This study represents the most comprehensive analysis of environmental levels of TRWP to date, with approximately 75 PM10 samples and 150 sediment samples collected on three continents. The results of this study will be used to understand the potential human and environmental risk of exposure to TRWP.

Keywords: tire, wear, PM10, sediment, road.
\end{abstract}




\section{Introduction}

Tire and road wear particles (TRWP) are produced from the interaction of tires with the roadway surface. This interaction is believed to change both the chemical composition and characteristics of the particles generated compared to the original tire tread due to heat and friction as well as incorporation of material from the road surface. Our previous research has found that TRWP are elongated particles with mineral incrustations from the road surface, which are quite different from tire particles produced by grinding or abrading of a tire tread (Kreider et al. [1]).

The goal of this research was to quantify global levels of TRWP in air and sediment at locations representative of human and ecological exposure in order to understand the potential for environmental health risk. Roadside soil, which is considered to be part of the roadway technosphere, was also analyzed to characterize local emissions. Watersheds were selected globally to represent a complete range of environments between watersheds and within watersheds. The sediment sampling domain was selected to characterize a wide range of ecological habitats and allow comparison of rural and urban areas as well as upstream and downstream locations. The air sampling campaign emphasized characterization of locations relevant to human receptors including residential developments, recreational areas, and near-road commercial properties including shopping districts. The roadside soil sample locations were selected for use in future fate and transport modeling, and some locations were representative of agricultural soils.

The continents of Europe, Asia, and North America were selected as geographically diverse locations of global tire consumption. A watershed selection methodology was developed to identify well characterized watersheds with sufficient diversity of traffic density as wells as ecological and human receptors to meet the objectives of the research. The selection metrics considered water quality, air quality, and area of the watershed.

Quantification of tread particles in the environment requires the identification and use of a chemical marker. In order to measure tread particles in the environment, an analytical method was developed for this research based on an initial quantitative pyrolysis-GC/MS protocol piloted by Bridgestone (Kitamura et al. [2], Harada et al. [3]). Pyrolysis gas chromatography/mass spectroscopy (GC/MS) is the thermal decomposition of a sample at high temperature, followed by quantification of the decomposition fragments by a mass-selective detector. The marker consists of butadiene and isoprene dimers specific to cross-linked natural rubber (NR), styrene-butadiene rubber (SBR), and butadiene rubber (BR) polymers, of which TRWP is the primary source in environmental media. Method development studies and analysis of the environmental samples were completed at the Chemical Evaluation Research Institute (CERI) in Saitama, Japan. 


\section{Methods}

The global sampling project consisted of four primary tasks: (1) watershed selection, (2) sample location selection, (3) field-sampling, and (4) sample analysis. These tasks were completed sequentially within each watershed. Environmental scientists local to each watershed conducted the preliminary watershed evaluation and reconnaissance necessary for selection of sample locations and implemented the field sampling plans.

\subsection{Watershed selection}

The watershed selection criteria included water quality, air quality, and spatial area of the watershed. Water quality was characterized by indicator metrics including dissolved oxygen, $\mathrm{pH}$, biological oxygen demand, nitrogen, and phosphorus (European Environment Agency [4]). The relative environmental quality of the largest watersheds in each of the three main geographical areas was compared to national criteria. Watersheds with typical or moderate water quality were identified, such that the target watershed was neither pristine nor severely polluted. Secondary metrics included:

- range of rural/remote endpoints to urban/metropolitan areas within the watershed;

- $\quad$ area large enough to include diverse receptor locations;

- areas likely to characterize an appreciable fraction of the national population;

- regular stream flow without significant droughts or floods;

- accessible environmental protection areas or recreational areas; and

- manageable watershed size such that field sampling could be completed in a two- to three-week mobilization effort.

Air quality within the watershed was evaluated using regional air quality databases. The frequency and number of $\mathrm{PM}_{10}$ monitoring stations within each watershed was considered to provide an indication of the amount of current and historical air monitoring data available and level of regulatory interest in the area. Typical $\mathrm{PM}_{10}$ concentrations in each area were used to determine the length of sampling time for air sample collection.

\subsection{Sample location selection}

Candidate sampling points within the watersheds were chosen for sediment, soil, and air in collaboration with the local field sampling teams. The teams reviewed geospatial data available in Geographical Information System (GIS) databases as well as other descriptive data available for the watershed. Potential sites were selected to represent a wide diversity of human receptors and ecological habitats. For all media, the presence of an identifiable vehicle traffic source was mandatory. Secondary evaluation metrics included proximity to accessible 
public land or access points, availability of historical sampling data, traffic load, population density, and land use.

For sediment sampling, sites were selected to include a variety of habitats, including main channel locations upstream and downstream of urban areas, environmental protection areas, and tributaries or lakes within the watershed. In air, the presence of human receptors was considered and sites were selected to capture a variety of settings where people are likely to be exposed to ambient air particulate. For soil sampling, sites were refined to encompass roadside variation across agricultural, wetland, and other regions. Other considerations for site selection included accessibility and availability of electric power for sampling equipment, accessibility of sample locations, and site security.

\subsection{Sample collection}

Sediment samples were collected either from the shore or by boat, depending on the accessibility characteristics of the site. Surface samples representative of recently deposited sediment were collected using a coring tool or sampling trowel. Samples were transferred to a basin, photographed, and placed into labeled jars. Sampling sheets and chain of custodies were completed for documentation. If no sediment could be collected at a location, the field crew identified the closest sedimentation zone adjacent to the target location. If such a zone could not be found within $100 \mathrm{~m}$, the location was not sampled and the team moved to the next location. The samples were stored in a cooler and wrapped to prevent breakage. The samples were then shipped to a local analytical lab for ancillary analysis and preparation for shipment to CERI for tread analysis. Approximately 50 sediment samples were collected for each watershed.

Air sampling for $\mathrm{PM}_{10}$ was conducted according to national regulatory standard methods. All samples were collected at a flow rate of $1 \mathrm{~m}^{3} /$ hour onto $47 \mathrm{~mm}$ quartz filters, chosen because they do not interfere with tread detection. Prior to sampling, the filters were allowed to stabilize for 48 hours at a controlled temperature and humidity. The filters were weighed after acclimatization and prior to use. All samples were collected for 24-48 hours. Afterwards, all filters, including field blanks were again acclimated in a controlled environment and then weighed. Filters were then packaged and shipped to CERI for tread analysis. Approximately $27 \mathrm{PM}_{10}$ samples were collected for each watershed. In addition, $\mathrm{PM}_{10}$ monitoring was conducted at 25 percent of the sites using a realtime dust analyzer.

Surface soil samples were collected at one to six inches below the surface with a shovel or trowel. For selected samples additional analysis was required (i.e. metals, etc), and the sample was split into multiple jars after collection. Moisture content, metals, particle size, and TOC were analyzed using standard methods by a local analytical laboratory. Samples were then oven dried, packaged, and shipped to CERI for tread analysis. 


\subsection{Sample analysis}

The TRWP analytical protocol for the global sampling project was based in part on an initial pyrolysis protocol developed by Bridgestone Corporation with a mass selective detector (Kitamura et al. [2] and Harada et al. [3]). Subsequent improvements to the method were based on a pilot field study with air, soil, and sediment samples collected from Miami, Florida in February 2010 at locations selected to represent areas where tread particles would likely be detected. As part of the pilot study, spike recoveries and replicates were analyzed, which revealed an effect of the matrix on the analytical reliability and lower than expected repeatability. Following the pilot study, the analytical method was modified to adopt a deuterated internal calibration standard.

A method detection limit (MDL) study was completed according to United States Environmental Protection Agency standard methods. The limit of detection of tread in soil and sediment was $14 \mu \mathrm{g} / \mathrm{g}$ dry weight based on a nominal $20 \mathrm{mg}$ sample. For air, the detection limit varies with mass of $\mathrm{PM}_{10}$ collected, but was $260 \mu \mathrm{g} / \mathrm{g}$ for whole quartz filter loaded with $1 \mathrm{mg}$ of particulate. More typically, an aliquot of $1 / 3$ of the filter was analyzed to provide an archive for future analyses with a resultant detection limit of $780 \mu \mathrm{g} / \mathrm{g}$. For samples where tread was not detected, the detection limit on a $\mu \mathrm{g} / \mathrm{m}^{3}$ basis ranged from 0.002 to $0.05 \mu \mathrm{g} / \mathrm{m}^{3}$.

All sediment and soil samples were characterized with respect to moisture content and a subset was characterized for ancillary parameters to characterize the watershed and assist with fate and transport and method evaluations. The ancillary parameters included total organic carbon, particle size distribution, and metal content (Ag, Al, As, Ba, Be, Cd, Co, Cr, Cu, Fe, Hg, Mn, Ni, Pb, Sb, Se, $\mathrm{Tl}, \mathrm{V}, \mathrm{Zn})$. All ancillary analyses were conducted according to standard national methods.

Summary statistics including mean, median, $90^{\text {th }}$ percentile and maximum result were prepared using SYSTAT Version 11. The data for each media were further evaluated using an analysis of variance (ANOVA) model to identify significant determinants of environmental concentrations of tread particles. The determinants evaluated included sample location, population density, traffic load and distance from the road and particle size distribution for soil and sediment. Significant pairwise differences were identified using the Tukey multiple comparison test. Censored data (samples less than the limit of detection) were included in the analysis using the regression on order statistics (ROS) method (USEPA [5]). Results from duplicate samples were averaged before statistical analysis.

\section{Results}

\subsection{Watershed selection}

Watersheds were selected from among the continents of Europe, Asia, and North America. A summary of selected major watersheds evaluated in this study is 
presented in Table 1. The first region assessed was Europe, where major watersheds were compared to identify an appropriate watershed for sample collection. Subsequent watersheds were evaluated for comparability to the European watershed with respect to water quality, population density, and scale to facilitate comparisons between geographical regions. Because all watersheds in Japan are smaller in scale than the larger watersheds in North America and Europe, comparability was assessed based on water quality and population density.

Table 1: $\quad$ Selected major watersheds considered in global sampling program.

\begin{tabular}{|c|c|c|c|c|}
\hline Watershed & $\begin{array}{l}\text { Selected } \\
\text { for Study }\end{array}$ & $\begin{array}{l}\text { Major River } \\
\text { Length (km) }\end{array}$ & $\begin{array}{c}\text { Basin Area } \\
\left(\mathrm{km}^{2}\right)\end{array}$ & Comment \\
\hline \multicolumn{5}{|c|}{ Europe } \\
\hline Seine River & Yes & 776 & 78,650 & $\begin{array}{l}\text { Diverse endpoints; generally } \\
\text { fair to good water quality. }\end{array}$ \\
\hline Po River & No & 650 & 74,000 & Heavy industry. \\
\hline Rhone River & No & 810 & 98,000 & Major wildlife area. \\
\hline Scheldt River & No & 355 & 22,000 & $\begin{array}{c}\text { Only } 0 \text { to } 20 \% \text { classified as } \\
\text { "not at risk". }\end{array}$ \\
\hline \multicolumn{5}{|l|}{ North America } \\
\hline $\begin{array}{c}\text { Chesapeake } \\
\text { Bay } \\
\text { (Susequehanna } \\
\text { River) } \\
\end{array}$ & Yes & 715 & 166,534 & $\begin{array}{l}\text { Diverse endpoints; similar in } \\
\text { scale and water quality } \\
\text { characteristics to Seine. }\end{array}$ \\
\hline $\begin{array}{l}\text { Mississippi } \\
\text { River }\end{array}$ & No & 3,734 & $2,981,076$ & Fair to poor water quality. \\
\hline Ohio River & No & 1,579 & 490,601 & $\begin{array}{c}\text { Generally good water quality; } \\
\text { larger in scale than Seine or } \\
\text { Chesapeake. }\end{array}$ \\
\hline \multicolumn{5}{|l|}{ Japan } \\
\hline Yodo River & Yes & 173 & 8,240 & $\begin{array}{l}\text { Diverse endpoints; similar in } \\
\text { water quality characteristics } \\
\text { to Seine. }\end{array}$ \\
\hline Arakawa River & No & 103 & 2,940 & $\begin{array}{l}\text { Heavy urbanization and poor } \\
\text { water quality in Tokyo. }\end{array}$ \\
\hline Ota River & No & 96 & 1,710 & Tire manufacturing facilities. \\
\hline Shonai River & No & 138 & 1,010 & Tire manufacturing facilities. \\
\hline Tama River & No & 75 & 1,240 & $\begin{array}{c}\text { Heavy urbanization and poor } \\
\text { water quality in Tokyo. }\end{array}$ \\
\hline
\end{tabular}

Based on the criteria described in Section 2.1, the Seine River, Chesapeake Bay and Yodo River watersheds were selected for inclusion in the study.

\subsection{Analytical results}

The results by environmental media are presented below. All tread concentrations were quantified by simultaneous analysis of the isoprene dimer and butadiene dimer markers. 


\subsubsection{Sediments}

A total of 149 sediment samples were collected in the three watersheds. Concentrations of tread particles in sediment ranged from $<14$ to 5,800 ppm (dry weight) with an overall average of $1000 \mathrm{ppm}$ and median concentration of 420 ppm (Table 2). Tread particles were detected in most samples, with an overall detection frequency of $97 \%$. Significant differences were identified between watersheds $(\mathrm{p}<0.0001)$, sampling areas $(\mathrm{p}<0.0001)$, by population density category $(p=0.03)$ and grain size classification $(p<0.0001)$. The concentration of tread particles observed in sediment in France was on average approximately a factor of 5 times higher than that observed in the United States and Japan. This result appears to be attributable primarily to higher silt/clay content of the samples collected in France as compared to the other countries. Grain size was determined for only a subset of samples; therefore, it was not possible to assess the simultaneous effect of population density/urbanization and grain size classification.

Table 2: $\quad$ Summary results for tread particles in sediment (ppm dry weight).

\begin{tabular}{|c|c|c|c|c|c|c|c|}
\hline Watershed & Area & (N) & $\begin{array}{c}\text { Detection } \\
\text { Frequency } \\
(\%)\end{array}$ & Avg. & Median & $\begin{array}{c}\mathbf{9 0}^{\text {th }} \\
\text { Percentile }\end{array}$ & Max. \\
\hline \multirow{4}{*}{$\begin{array}{c}\text { Seine } \\
\text { (France) }\end{array}$} & Troyes & 13 & $92 \%$ & 2000 & 2100 & 3400 & 3500 \\
\hline & St. Dizier & 10 & $100 \%$ & 2200 & 1000 & 4900 & 5400 \\
\hline & Paris & 13 & $100 \%$ & 3100 & 3100 & 5500 & 5800 \\
\hline & Rouen & 13 & $100 \%$ & 1700 & 1600 & 4000 & 4700 \\
\hline \multirow{2}{*}{$\begin{array}{l}\text { Chesapeake } \\
\text { (USA) }\end{array}$} & Harrisburg & 13 & $100 \%$ & 400 & 290 & 890 & 970 \\
\hline & $\begin{array}{l}\text { Washington, } \\
\text { D.C. }\end{array}$ & 37 & $100 \%$ & 470 & 260 & 1200 & 2200 \\
\hline \multirow{4}{*}{$\begin{array}{l}\text { Yodo } \\
\text { (Japan) }\end{array}$} & Shiga & 13 & $92 \%$ & 1000 & 1000 & 2100 & 2300 \\
\hline & Kyoto/Mie & 22 & $95 \%$ & 180 & 120 & 450 & 880 \\
\hline & Hyogo & 5 & $100 \%$ & 110 & 80 & 180 & 180 \\
\hline & Osaka & 10 & $90 \%$ & 160 & 23 & 560 & 680 \\
\hline Seine & All Areas & 49 & $98 \%$ & 2200 & 2000 & 4900 & 5800 \\
\hline Chesapeake & All Areas & 50 & $100 \%$ & 460 & 260 & 1100 & 2200 \\
\hline Yodo & All Areas & 50 & $94 \%$ & 380 & 130 & 1100 & 2300 \\
\hline \multirow[t]{2}{*}{ All } & \begin{tabular}{|c|} 
Low to \\
Moderate \\
Population \\
Density $(<3000$ \\
$\left.\mathrm{km}^{-2}\right)$ \\
\end{tabular} & 89 & $98 \%$ & 670 & 280 & 1500 & 5400 \\
\hline & \begin{tabular}{|c|} 
High \\
Population \\
Density $(\geq 3000$ \\
$\left.\mathrm{km}^{-2}\right)$ \\
\end{tabular} & 60 & $97 \%$ & 1500 & 790 & 3700 & 5800 \\
\hline All & All Areas & 149 & $97 \%$ & 1000 & 420 & 3100 & 5800 \\
\hline
\end{tabular}

Tread particle concentrations were on average greater in downstream locations as compared to upstream locations relative to city centers, however, this difference was not statistically significant, most likely due to the importance of grain size on observed tread particle concentration and the wide dispersive 
release of tread particles in the environment. Based on the magnitude of the differences in average tread concentration between countries and between grain size classifications, the data were further summarized by these two factors and included in an ANOVA model. Overall, locations classified as silt or clay based on grain size had tread particle concentrations approximately a factor of 10 times higher than locations where the sample was characterized as sand. The pair-wise comparison showed significant differences in tread concentration between sand and silt/clay classifications within countries $(p<0.05)$ but no significant differences between countries within a soil classification (Figure 5). On average, the total organic carbon content of the soil varied with grain size by a factor of 4 with a content of $2.8 \%$ at locations characterized as silt or clay and $0.7 \%$ at locations characterized as sand. These results suggest that soil grain size and/or organic carbon content of the sediment are important determinants of tread particle concentration in sediment.

Metals were quantified in 45 sediment samples (i.e. 15 samples in each country) and compared to tread particle concentrations. Correlation analysis between each metal and the trefd marker revealed statistically significant correlation coefficients for aluminum and cobalt in all three countries. Aluminum is present in the pavement and in TRWP at a concentration greater than $3 \%$ (as a result of the embedded pavement pieces), while cobalt is released to the environment in vehicle exhaust. Zinc is used in tires and the absence of a strong correlation in France and Japan may reflect the importance of non-tread sources to observed levels. In general, the tread concentrations were highly correlated with at least one metal associated with TRWP, vehicle exhaust and brake usage except in France where brake sources were not correlated with the marker (including iron from brake discs).

\subsubsection{Air}

A total of 81 air samples from the three watersheds were available for analysis. The results indicated that tread is small percentage of $\mathrm{PM}_{10}$ (ppm basis) and low in terms of absolute magnitude $\left(\mu \mathrm{g} / \mathrm{m}^{3}\right.$ basis). Overall, the mean air concentration of tread in $\mathrm{PM}_{10}$ was $0.080\left(\mu \mathrm{g} / \mathrm{m}^{3}\right)$ and the median was 0.041 $\mu \mathrm{g} / \mathrm{m}^{3}$ with $90^{\text {th }}$ percentiles less than $0.20\left(\mu \mathrm{g} / \mathrm{m}^{3}\right)$ (Table 3$)$. The range of measured air concentrations was $<0.002 \mu \mathrm{g} / \mathrm{m}^{3}$ to $0.67 \mu \mathrm{g} / \mathrm{m}^{3}$. On average, TRWP was a minor contributor to $\mathrm{PM}_{10}$ with an average contribution of $0.6 \%$ and range of $0.07 \%$ to $1.9 \%$. The real time $\mathrm{PM}_{10}$ monitoring performed at selected locations confirmed the gravimetric $\mathrm{PM}_{10}$ results.

The air concentration results were categorized by relative traffic load, population density and distance from the road. Tread concentrations in areas with population densities less than 3000 people $/ \mathrm{km}^{2}$ were generally insensitive to traffic load and distance from the road and were less than $0.07 \mu \mathrm{g} / \mathrm{m}^{3}$ on average. Tread concentrations in areas with 3000 people $/ \mathrm{km}^{2}$ or greater were slightly higher in some cases. For example, an average of $0.12 \mu \mathrm{g} / \mathrm{m}^{3}$ for locations within $10 \mathrm{~m}$ of the road and traffic exceeding 25000 vehicles/day was observed. An increasing trend with traffic load and population density was observed, but this trend was not statistically significant. Clear trends by type of road 
Table 3: $\quad$ Summary air concentration results for tread particles in $\mathrm{PM}_{10}$.

\begin{tabular}{|c|c|c|c|c|c|c|c|}
\hline \multirow{2}{*}{ Watershed } & Area & $(\mathrm{N})$ & $\begin{array}{c}\text { Detection } \\
\text { Frequency } \\
(\%)\end{array}$ & $\begin{array}{c}\text { Average } \\
\left(\mu \mathrm{g} / \mathrm{m}^{3}\right)\end{array}$ & $\begin{array}{c}\text { Median } \\
\left(\mu \mathrm{g} / \mathrm{m}^{3}\right)\end{array}$ & $\begin{array}{c}90^{\text {th }} \\
\text { Percentile } \\
\left(\mu \mathrm{g} / \mathrm{m}^{3}\right)\end{array}$ & $\begin{array}{c}\text { Maximum } \\
\left(\mu \mathrm{g} / \mathrm{m}^{3}\right)\end{array}$ \\
\hline \multirow{3}{*}{$\begin{array}{c}\text { Seine } \\
\text { (France) }\end{array}$} & Troyes & 6 & $83 \%$ & 0.35 & 0.38 & 0.67 & 0.67 \\
\cline { 2 - 8 } & Reims & 6 & $67 \%$ & 0.083 & 0.021 & 0.35 & 0.35 \\
\cline { 2 - 8 } & Paris & 9 & $78 \%$ & 0.023 & 0.019 & 0.056 & 0.056 \\
\cline { 2 - 8 } & Rouen & 6 & $50 \%$ & 0.085 & 0.0047 & 0.43 & 0.43 \\
\hline $\begin{array}{c}\text { Chesapeake } \\
\text { (USA) }\end{array}$ & Harrisburg & 9 & $78 \%$ & 0.065 & 0.057 & 0.16 & 0.16 \\
\cline { 2 - 8 }$\left(\begin{array}{c}\text { Yodo } \\
\text { Yapan) }\end{array}\right.$ & $\begin{array}{c}\text { Dhington, } \\
\text { Diga/Lake }\end{array}$ & 18 & $83 \%$ & 0.069 & 0.046 & 0.13 & 0.24 \\
\cline { 2 - 8 } & Kyoto/Mie & 10 & $70 \%$ & 0.047 & 0.037 & 0.063 & 0.11 \\
\cline { 2 - 8 } & Hyogo/Osaka & 13 & $62 \%$ & 0.042 & 0.039 & 0.075 & 0.076 \\
\hline Seine & All Areas & 27 & $70 \%$ & 0.12 & 0.023 & 0.44 & 0.67 \\
\hline Chesapeake & All Areas & 27 & $81 \%$ & 0.068 & 0.057 & 0.13 & 0.24 \\
\hline Yodo & All Areas & 27 & $70 \%$ & 0.051 & 0.042 & 0.10 & 0.16 \\
\hline All Areas & All Areas & 81 & $74 \%$ & 0.080 & 0.041 & 0.16 & 0.67 \\
\hline
\end{tabular}

(controlled access, national highways, primary, secondary and local) were not observed, and this outcome was attributed to the relatively low concentrations of TRWP in the samples; diminishing the likelihood of discriminating by these metrics.

\subsubsection{Roadside surface soil}

Sixty-nine roadside soil samples were collected from among the three watersheds. The average concentration of tread in the soil in the three watersheds ranged from 680 to $4,600 \mathrm{ppm}$ with an overall average of $1,900 \mathrm{ppm}$. Individual sample result ranged from 100 to $10000 \mathrm{ppm}$ dry weight, with a detection frequency of $100 \%$. Traffic density and distance from the roadway were significant and additive predictors of tread concentration in the ANOVA analysis. The pair wise comparison showed that high traffic load and short distance to the road resulted in statistically higher tread concentrations as compared to low traffic load and high distance from the road.

\section{Discussion}

The overall goal of this research to identify and quantify TRWP impacts at locations representative of potential human and ecological exposure has been met. With the assistance of three global field teams, samples have been collected in relevant receptor locations representing a wide diversity of locales. The land use considered in the study included rural, agricultural, sub-urban, urban, and major metropolitan areas with populations greater than 10 million people. Within each region of the world, the sampling has included areas of ecological interest and national parks, and varied from remote to urban. Although the sampling 
program represents a cross-section in time, the diversity of geographical locations and demographic characteristics included in the sampling plan should give confidence that sufficient data has been assembled to understand global environmental exposure.

The marker has been developed to quantify tread particles in the environment based on tread polymer content of approximately 50 percent. An analysis of roadway particles indicates a polymer content of approximately 20 to 25 percent by weight (Kreider et al. [1]). Therefore, TRWP concentrations (including embedded non-tread material from the roadway) are up a factor of two times higher than the tread particle concentrations quantified by the analytical method. For example, the average tread particle concentration of $0.25 \mu \mathrm{g} / \mathrm{m}^{3}$ on a tread basis would be approximately $0.50 \mu \mathrm{g} / \mathrm{m}^{3}$ if reported as TRWP. We have chosen to report the results on a tread basis for consistency with prior literature and to minimize the number of assumptions required in the method to extrapolate to TRWP.

The strong correlation between tread particle concentration in sediment and total organic carbon and sediment grain size reduced our ability to statistically assess traffic load and other likely determinants due high spatial variability in these parameters within a watershed and availability of this data for only a subset of the entire dataset. The absence of a clear trend upstream and downstream of urban centers suggests that TRWP are widely dispersed in the environment such that organic content and grain size may be a better predictor of tread particle concentration than nearby traffic load or location relative to the urban center.

Concentrations of tread particles in sediment have been reported in the literature, however, the results of these prior studies are not considered to have high reliability. For example, our work with the organic zinc marker showed that inorganic zinc dispersed as a colloid in the dichloromethane extraction such that inorganic and organic zinc were not properly separated. Benzothiazole based markers methods are difficult to refine based on differences in tire formulations, background sources of benzothiazole compounds in general, and the propensity for benzothiazole compounds to dissolute from the tread matrix. To increase the confidence in the results of this study taking into account the lack of reliable data for comparison, we have adopted the use of a deuterated internal standard in the analysis. The use of an internal standard ensures that the effect of the matrix is automatically corrected in the analysis.

With regard to air, the air concentration of tread in the $\mathrm{PM}_{10}$ fraction was low with an overall median airborne concentration of less than $0.1 \mu \mathrm{g} / \mathrm{m}^{3}$ and overall $90^{\text {th }}$ percentile concentration less than $0.2 \mu \mathrm{g} / \mathrm{m}^{3}$ (Table 9). Across sub-areas, the average contribution of tread to $\mathrm{PM}_{10}$ levels ranged from 0.07 to 1.9 percent, with the highest contribution observed in Maryland. This area included one outlier where $\mathrm{PM}_{10}$ concentration was very low $\left(0.9 \mu \mathrm{g} / \mathrm{m}^{3}\right)$ and tread concentration was also low $\left(0.1 \mu \mathrm{g} / \mathrm{m}^{3}\right)$ but contributed $11 \%$ to total $\mathrm{PM}_{10}$. The average percent contribution in Maryland without this sample was $0.4 \%$. These results illustrate the importance of considering simultaneously the contribution of tread to total $\mathrm{PM}_{10}$ as well as the concentration of tread particulate in air. Knowledge of only the contribution of tread particulate to total $\mathrm{PM}_{10}$ alone does 
not provide sufficient information to estimate the concentration of tread in air. The most reliable approach to estimate exposure is to measure the concentration of tread particles in $\mathrm{PM}_{10}$ with simultaneous determination of total $\mathrm{PM}_{10}$, as has been done in this study.

Previously reported concentrations of tread particles in air were summarized in the State of Knowledge Report (ChemRisk [6]). In general, the percent contribution of tread to $\mathrm{PM}_{10}$ has been reported in the range of 1 to 10 percent. Our global study indicates a central tendency of about 0.55 percent and a range of sub-area averages of 0.07 to 1.9 percent which is consistent with the results of the Japanese Automobile Tyre Manufactures Association (JATMA) and Japan Clear Air Program research, which reported a range of 0.6 to 1.3 percent for the $<7 \mu \mathrm{m}$ fraction, JATMA [7]. In that study, pyrolysis markers were used, but the results were based on monomers and use of an external standard as compared to the use of dimers and an internal standard in this study. In terms of absolute concentration, the JATMA range of 0.2 to $1.3 \mu \mathrm{g} / \mathrm{m}^{3}$ for the $<7 \mu \mathrm{m}$ fraction is similar to the average results by sub-area of 0.02 to $0.35 \mu \mathrm{g} / \mathrm{m}^{3}$ in this study. The slightly higher results in the JATMA study are likely attributable to the use of monomers, which are less specific to tread polymer.

Soil samples collected along roadways within the three watersheds a showed an additive contribution of distance from the road and traffic load to average tread concentration. The overall average concentration was 1900 ppm dry weight with a range averaging from $780 \mathrm{ppm}$ to $4300 \mathrm{ppm}$ depending on distance from the road and traffic load. The data collected within the roadway technosphere should be helpful for understand the contribution of TRWP to sediments and air (for example, soil resuspension).

\section{Conclusions}

In summary, the data collected in this study are expected to be extremely useful in the completion of a human health and ecological risk assessment for TRWP. Taking into account the findings of this study, including important determinants of environmental concentration in the three media, recommended exposure values will be developed for use in risk assessment.

\section{Acknowledgement}

The authors of this study wish to thank the environmental scientists from AMEC Earth and Environmental, Inc., Golder Associates and the Japan Environmental Sanitation Center (JESC) for assisting with the sample collection in the United States, France and Japan, respectively.

\section{References}

[1] Kreider ML, JM, BL McAtee, LI Sweet, BL Finley.. "Physical and chemical characterization of tire-related particles: Comparison of particles generated using different methodologies." Science of the Total Environment 408(3): 652-659. 2010. 
[2] Kitamura, Y, C Kuroiwa, M Harada, N Kato. Analysis of Rubber Fraction in Suspended Particulate Matter (SPM) on Road, American Chemical Society, 115516 th St, NW, Washington, DC, 20036, USA. 2007.

[3] Harada, M, T Shibata, JM Panko, KM Unice. Analysis Methodology of Rubber Fraction in Fine Particles. Fall 176th Technical Meeting of the Rubber Division of the American Chemical Society, Inc. Pittsburgh, PA. 2009.

[4] European Environment Agency. "Data and maps." 2010, from http://www.eea.europa.eu/data-and-maps. 2009.

[5] United States Environmental Protection Agency (USEPA). ProUCL Version 4.00 User's Guide. Washington, D.C.: USEPA, 2007.

[6] ChemRisk. State of Knowledge Report for Priority Tire Materials and Tire Wear Particles. Pittsburgh, PA, ChemRisk. http://www.wbcsd.org/Pages/EDocument/EDocumentDetails.aspx?ID=54\& NoSearchContextKey=true. 2008.

[7] Japan Automobile Tyre Manufacturers Association, Inc (JATMA). Source apportionment study performed as part of the Japan Clean Air Program (JCAP). 2001. 